\title{
A fisiopsicologia de Nietzsche: o diagnóstico e a elevação da cultura como tarefa do médico filosófico
}

The Physiopsychology of Nietzsche: the diagnosis and the cultural elevation as the task of the philosophical physician

\section{Wilson Antonio Frezzatti Jr. Universidade Estadual do Oeste do Paraná}

\section{RESUMO}

As produções humanas, segundo Nietzsche, são expressões fisiológicas, ou seja, expressões de um conjunto de impulsos em luta por mais potência. Essa perspectiva ocupa papel central nas reflexões da maturidade do filósofo: sua fisiopsicologia desenvolve um diagnóstico das produções culturais e indica quais manifestações possuem um caráter saudável e quais delas são doentias. Nietzsche assume o papel de médico na medida em que se preocupa com um medicamento, isto é, com um contra-ideal, com um adversário da civilização entendida enquanto domesticação dos impulsos humanos. O médico nietzschiano antagoniza-se àquele proposto pela tradição filosófica: não é um médico de almas.

\section{PALAVRAS-CHAVE}

Civilização; Cultura;

Fisiopsicologia;

Médico filosófico;

Vontade de potência.

\section{ABSTRACT}

Human productions, according to Nietzsche, are physiological expressions, i.e. expressions of a multiplicity of drives in struggle for expansion of power. This perspective plays a central role in the reflections of the maturity of the philosopher: his Physiopsychology develops a diagnosis of the cultural productions and indicate which manifestations have a healthy character and which of them are sick. Nietzsche assumes the role of physician inasmuch as he is concerned with a remedy, with a counter-ideal, with an adversary of the civilization understood as domestication of the human drives. The Nietzschean physician antagonizes that one proposed by the philosophical tradition: he is not a physician of souls.

\section{KEY WORDS}

Civilization; Culture;

Physiopsychology;

Philosophical Physician;

Will to Ptower. 
A figura do médico está presente em quase toda a obra de Nietzsche, tanto nos textos publicados quanto nos fragmentos póstumos. Sua presença ocorre desde simples analogias até um papel central nas propostas de uma nova filosofia e de superação do pensamento vigente, tornando-se uma personagem conceitual. Neste artigo, daremos destaque ao médico associado à fisiopsicologia nietzschiana, a qual, conforme Para além de Bem e Mal $\$ 23$, é a morfologia e a doutrina do desenvolvimento da vontade de potência (Morphologie und Entwicklungslehre des

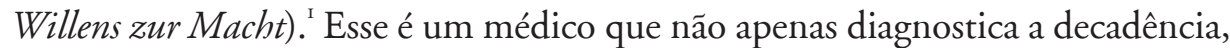
mas também preconiza a superação desse estado mórbido. No contexto dessa perspectiva, entendemos que Nietzsche propõe um ciclo cultural que chamamos "ciclo vital da cultura". É importante para o filósofo alemão, ao investigar as culturas de sua época ou anteriores, como a grega, identificar se a cultura em questão está em elevação ou em decadência para poder distinguir as ações que possam contribuir para a manutenção da decadência daquelas que possam propiciar sua superação.

Analogias com o papel e a atuação do médico são muito comuns nos textos nietzschianos. Em um fragmento póstumo de I875, temos a seguinte comparação: "Nossos filólogos se assemelham aos verdadeiros educadores tanto quanto os curandeiros dos povos selvagens aos verdadeiros médicos". ${ }^{2}$ Em Aurora, no aforismo "A comédia da compaixão", a comparação é com a compaixão: "Por mais que gostemos de nos importar com um infeliz: em sua presença representamos sempre um pouco de comédia, não dizemos muitas coisas que pensamos e nem como as pensamos, com aquela cautela do médico junto ao leito do enfermo grave". ${ }^{3}$ Outro exemplo: "Distanciar-se dos fenômenos morais do mesmo modo que o médico se mantém distante da crença nas bruxas e da doutrina 'da garra do diabo' ". 4

Porém, o filósofo alemão não se restringe às analogias. Desde seus primeiros textos, Nietzsche propõe a necessidade de um médico filosófico para cuidar da cultura, o qual seria antagonista do médico de almas da tradição estoica ou epicurista. Estes médicos são considerados pelo filósofo alemão como charlatães: "Deve-se ter cuidado com os médicos charlatães [Pfuscher-Ärzte], (a maioria é composta pelos eruditos)". 'Eles são charlatães porque enganam que são capazes de curar: "Os médicos mais perigosos — Os médicos mais perigosos

I Cf. Para além de Bem e Mal \$23, KSA 5.38. Sobre a fisiopsicologia nietzschiana e a sua relação com a psicofisiologia francesa, cf. Frezzatti, 2010 e $2014 a$.

2 Fragmento Póstumo 5 [160] da primavera-verão de I875, KsA 8. 84-85.

3 Aurora $\$ 383$, KSA 3.248.

4 Fragmento Póstumo 26 [23] do verão- outono de I884, KSA II.I55.

5 Fragmento Póstumo 3I [8] do outono de I873-inverno de I873-I874, KSA 7.75I. 
são os que, como comediantes [Schauspieler] natos, imitam o médico nato com a perfeita arte do engano". Jesus também é visto como um médico da alma que tem uma crença numa estúpida e ineficiente medicina universal: para combater a sensualidade (Sinnlichkeit), arranque-se os olhos. ${ }^{7}$

Nietzsche, em Schopenhauer como educador, pergunta quem será, em sua época, médico o bastante para reconhecer que a dedicação cega da juventude às ciências não pode originar-se de um pretenso impulso à verdade [Trieb zur Wahrheit], pois um impulso não poderia visar a algo puro, sem consequências, como é o caso do conhecimento. A investigação sobre o erudito [Gelehrte] deve mostrar que ele não é movido por uma disposição desinteressada, por buscar a verdade pela verdade: o erudito é um amontoado de impulsos e estímulos muito variados. Nietzsche enumera treze desses impulsos e estímulos, e cada um deles se constitui de um aglomerado de características: a curiosidade forte e o impulso de contradição; o olhar sagaz para as coisas próximas e o míope para o longínquo; o prosaísmo; a aridez de sentimento, ou seja, a não percepção do excesso de sofrimento que o excesso de conhecimento causa; a modéstia; a fidelidade aos mestres; a especialização como hábito de fazer sempre o mesmo; a fuga do tédio; a busca de um ganha-pão; o respeito aos colegas e o medo de sua desaprovação; a vaidade; o impulso ao acaso; o impulso à justiça. Em consequência dessa mescla, temos um infecundo servidor da verdade pura, e o que é pior, com ódio do que é fecundo, ou seja, do gênio ${ }^{8}$ - os eruditos querem apalpá-lo, dissecá-lo e matálo. As épocas profundamente doentes e desanimadas estimam o erudito como sendo o homem superior. Esse é o caso da época de Nietzsche, que não sabe o que é cultura [Kultur], em que há um forte antagonismo entre Estado e cultura. $\mathrm{O}$ Estado patrocina apenas a instrução [Unterricht] e a formação [Bildung] que visam apenas ao lucro. No entanto, a apatia e a confusão dessa época, sob influência do cristianismo' impedem que os melhores sejam capazes de disciplinar e de serem guias de outras pessoas. Nietzsche clama por um médico que seja um verdadeiro

6 Humano, demasiado Humano, I, $\$ 306$, KSA 2.24I. Outros trechos indicam o charlatanismo dos médicos da alma tradicionais e os seus perigos: "O perigo do médico - É necessário termos nascido para o nosso médico, senão morremos devido ao nosso médico" (Humano, demasiado Humano, I, $\$$ 573, KSA 2.330; e "Sim, queremos despertar e curar, mas não de modo que os despertos tenham que voltar a dormir e os curados pereçam devido à cura" (Fragmento Póstumo I2 [189] do outono de I881, KSA 9.608).

7 Cf. O Andarilho e sua Sombra $\$ 83$, KSA 2.589-590. Nietzsche refere-se a Mateus 5:29-30 e I8:9.

8 Sobre a concepção nietzschiana de gênio, cf. Nasser, 20I2 e Frezzatti, 2006, pp. I43-I8I.

9 Junto com a insensibilidade e a repugnância ao natural, há uma atração pelo natural como busca por um ponto de apoio. Em consequência desse paradoxo, temos uma confusão na alma moderna, que a condena a ser estéril e sem alegria (cf. Schopenhauer como educador $\$ 2$, KSA I.345-348). 
filósofo e educador [Erzieher] moral: "onde estão os médicos da humanidade moderna que, em si mesmos, tenham os seus pés tão firmes e saudáveis que ainda poderiam cuidar de alguma outra pessoa e a guiar pela mão?”. Io É nessa busca que Nietzsche diz encontrar Schopenhauer, o modelo de mestre de si mesmo, aquele que une pensamento e vida. Assim, tal mestre não é um médico que busca a ataraxia e a epoche, como faziam os médicos estoicos e epicuristas.

Nesse contexto, "o filósofo como médico da cultura [Artz der Cultur]" deve investir contra o predomínio da erudição, deve reprimir os efeitos bárbaros do impulso do saber [Wissenstrieb], isto é, a destruição do estilo e preparar o surgimento do gênio. ${ }^{\text {I2 }}$ Nessa mesma época, Nietzsche define cultura como: "Cultura [Kultur] é, sobretudo, unidade de estilo artístico [Einheit des künstlerischen Stiles] em todas as manifestações da vida de um povo". ${ }^{13}$ A importação e a mistura de manifestações culturais de diversas procedências destrói a genuinidade de um povo: trata-se não de uma cultura inferior, mas da própria ausência de cultura. A barbárie, nesse momento da produção nietzschiana, é a ausência de estilo e, portanto, é o oposto da cultura.

Em todo lugar, para o filósofo alemão, há sintomas de atrofia da formação e

IO Schopenhauer como educador $\$ 2$, KSA I.345-346. O médico como alguém sadio que se encontra acima dos doentes e, por isso mesmo, capaz de curá-los não pode ser aceito no contexto teórico de Genealogia da Moral. Não faz parte da tarefa dos sãos ser médico dos doentes. Os sãos estão comprometidos com o futuro do homem e não podem ser vítimas do grande nojo do homem e da grande compaixão do homem. Eles devem ser portadores do pathos da distância. Os médicos dos doentes devem ser também doentes: esse é o sentido do sacerdote ascético. Para dominar os que sofrem e curá-los, esse médico deve ferir antes: envenena a ferida, piorando a doença, ou seja, o sacerdote ascético muda a direção do ressentimento, sendo que o próprio doente passa a ser culpado de sua dor (má consciência). Entretanto, aqui não temos nem uma verdadeira cura nem um verdadeiro médico, pois há apenas entorpecimento (cf. Genealogia da Moral, "Terceira dissertação", \ I4-I5 e I7, KSA 5.367-375 e 377-382). Em Crepúsculo dos Ídolos, "O problema de Sócrates", $\$$ II, Sócrates é igualmente um pseudomédico. Ele parecia ser um médico, um salvador e acreditava sair da décadence lutando contra ela por meio da racionalidade e da consciência, que resistiam aos instintos (cf. KSA 6.72-73). Ao morrer, segundo Nietzsche, o filósofo grego sabia que estava doente, pois lembra Críton de sacrificar um galo a Asclépio: "Sócrates não é um médico, ele murmurou para si mesmo: a morte somente é medico aqui... Sócrates, ele mesmo, apenas esteve doente por longo tempo...” (KSA 6.73).

II Fragmento Póstumo 23 [I5] do inverno de I872-I873, KSA 7.545. Para mostrar que a preocupação do médico nietzschiano parece estar mais focada na cultura que no indivíduo, apresentamos o Fragmento Póstumo 3 [I] I59 do verão-outono de I882: "Nos indivíduos, a loucura [Irrsinn] é rara — mas nos grupos, partidos, povos, épocas, é a regra: e por isso os historiadores não têm falado da loucura até hoje. Mas chegará o tempo em que os médicos escreverão a história" (KSA IO.72).

I2 Cf. Fragmento Póstumo 23 [I4] inverno I872-I873, KSA 7.544-545.

I3 David Strauss, o devoto e o escritor $\$$ I, KSA I.I63. 
um completo laissez faire das ciências: recuo da religião; pressa; lutas nacionais ${ }^{14}$; nas classes cultas [gebildeten Ständen], há prevalência do dinheiro e falta de amor e de magnanimidade; a arte e a ciência estão a serviço da barbárie (ausência de estilo); etc. Os eruditos impedem o trabalho dos médicos e negam a existência da doença. ${ }^{\text {Is }}$ A cultura, segundo o jovem Nietzsche, só pode surgir do significado central de uma arte ou de uma obra de arte. A tarefa da filosofia é preparar a consideração de mundo [Weltbetrachtung] dessa obra de arte. O Estado deveria assumir essa tarefa, da mesma maneira que, conforme acredita Nietzsche, o antigo Estado grego aristocrático. Ele deve harmonizar o desenvolvimento das várias forças existentes com o desenvolvimento das poucas forças que correspondem aos fins do próprio Estado. ${ }^{16} \mathrm{O}$ estado cultural [Kulturstaat] deve impedir que os fortes se destruam entre si, unindo-os numa meta comum. Esse alvo, difícil e artificial, degenera-se muito facilmente, e é tarefa do médico cuidar dessa harmonia. $\mathrm{O}$ médico da cultura, por meio da filosofia, deve aliar essas forças, impedir que a filosofia destrua a si mesma, a cultura e a felicidade.

Assim como Schopenhauer, esses filósofos-médicos devem ser filósofos para si, e, ao invés do apolíneo "Conhece-te a ti mesmo", Nietzsche exorta: "Médico, cura-te a ti mesmo". ${ }^{17}$ Essa cura envolve, entre outras atitudes, conhecer o sofrimento para atenuá-lo e evitar a compaixão, que redobra o sofrimento. ${ }^{18} \mathrm{~A}$ compaixão talvez seja a origem da incapacidade dos médicos filosóficos ajudarem outras pessoas, ela é um perigo a ser evitado: "Quem quiser muito, como médico, servir à humanidade em qualquer sentido deverá ser muito cauteloso com esse sentimento [a compaixão], - ele o paralisa em todos os momentos decisivos e prende sua sabedoria e sua precisa mão benéfica" ${ }^{19} \mathrm{O}$ médico deve evitar não apenas a compaixão, deve nos livrar também dos sentimentos de culpa e vingança e dos conceitos de pecado e castigo. ${ }^{\circ 0}$ Ao invés da compaixão, como um bom médico, deve fazer algo para compartilhamento da alegria, o que multiplicaria a força do mundo [die Kraft der Welt]: devemos rir para não sermos contaminados

I4 Sobre o nacionalismo e cultura em Nietzsche, cf. Silva Jr., 2007, pp. 99-II8.

I5 Cf. Fragmento Póstumo 29 [222] do verão-outono de I872-I873, KSA 7.718-719.

i6 Cf. Fragmento Póstumo 29 [222] do verão-outono de I872-I873, KSA 7.718-719.

I7 Fragmento Póstumo 29 [213] do verão-outono de 1872-1873, KSA 7.715. Essa postura, posteriormente, será uma característica importante da grande saúde. Em Assim falava Zaratustra, no discurso "Da virtude que dá” \$2, temos também a exortação ao cuidado de si: "Médico, ajuda a ti próprio: assim ajudas também a teu doente. Seja esta a tua melhor ajuda, que ele veja com seus próprios olhos aquele que cura a si próprio" (KSA 4.IOO). Essa exortação parafraseia Lucas 4:23, o evangelista médico e companheiro de Paulo.

I8 Cf. Fragmento Póstumo 2 [35] primavera I88o, Nietzsche, I999, v. 9, p. 39.

I9 Aurora $\$$ I34, KSA 3.I25.

20 Cf. Aurora $\$$ 202, KSA 3.I28. 
pela desolação ${ }^{21}$. O efeito depressivo da compaixão sobre a vida ainda é tema em O Anticristo $\$ 7$ : "Ser médico nisso, ser inexorável nisso, conduzir o escalpelo nisso — isso pertence a nós, essa é a nossa espécie de amor aos homens, assim nós somos filósofos, nós hiperbóreos!" . ${ }^{22}$ No contexto teórico dessa obra, a compaixão entrava o processo seletivo [Selection], ou seja, conserva a degeneração da configuração de impulsos que está madura para a dissolução. ${ }^{23}$ Os hiperbóreos são, para o filósofo alemão, o tipo que se antagoniza ao decadente homem moderno, e são ainda aqueles que estão desvinculados dos valores vigentes. ${ }^{24}$

Em Humano, demasiado Humano, agora em contexto teórico diferente de seus primeiros textos, a busca pelo médico filosófico continua. No aforismo 243, intitulado "O futuro do médico", Nietzsche afirma que os médicos da alma são rejeitados e que ao novo médico não basta ser um bom diagnosticador, deve reunir as habilidades e os artifícios de outros profissionais: uma eloquência adaptada a cada paciente; uma virilidade que afaste a pusilanimidade do doente; uma flexibilidade diplomática para mediar os que precisam de alegria e os que podem doá-la; e sutileza de um advogado que entenda os segredos da alma sem denunciá-los. Sua tarefa é ainda fomentar a alegria e a fecundidade do espírito, mas por meio de uma "aristocracia" no corpo e no espírito.

"Onde estão os novos médicos da alma?", pergunta Nietzsche em Aurora $\$ 52 .{ }^{25}$ Os antigos médicos da alma pioraram as doenças humanas ao combatêlas. Eles são charlatães: suas consolações são apenas anestésicos e inebriantes que produzem alívio momentâneo apenas.

Ainda no prefácio de I886 de $A$ gaia Ciência, Nietzsche faz um apelo ao

2 I Cf. Fragmento Póstumo 7 [285] fins de I880, KSA 9.377-378.

22 KSA 6.I73.

23 Cf. $O$ Anticristo $\$ 47$, KSA 6.225-226. Nesses dois parágrafos de $O$ Anticristo, vemos a função do médico unida à do filósofo $(\$ 7)$ e à do filólogo (\$ 47): "Com efeito, não se é filólogo e médico sem ser também ao mesmo tempo anticristão. Como filólogo, olha-se atrás dos 'livros sagrados'; como médico, atrás da depravação fisiológica do cristão típico. O médico diz 'incurável'; o filólogo, 'impostura'..." ( $O$ Anticristo \$ 47, KSA 6.226).

24 Em $O$ Anticristo $₫$ I: "Olhemo-nos na face. Nós somos hiperbóreos, — sabemos bastante bem quanto apartados vivemos. 'Nem por terra nem por água encontrarás o caminho que conduz aos Hiperbóreos': já sabia Píndaro sobre nós. Além do norte, do gelo, da morte - nossa vida, nossa felicidade... Nós descobrimos a felicidade, nós sabemos o caminho, nós achamos a saída de milênios inteiros de labirinto. Quem mais a encontrou? — O homem moderno porventura? 'Eu não sei o que fazer; sou tudo aquilo que não sabe o que fazer’ — geme o homem moderno... Dessa modernidade nós estávamos doentes, — da paz podre, do compromisso covarde" (KSA 6.226). Na mitologia grega, os hiperbóreos são um povo que habita além do extremo norte, além da região na qual soprava o vento norte (Bóreas). Nessa região mítica, não haveria noite, temperaturas excessivas, guerra, doenças. Eram dedicados a Apolo e viveriam uma eterna felicidade, cantando e dançando.

25 KSA 3.56 . 
surgimento de um médico para a cultura:

Eu ainda espero que um médico filosófico, no sentido excepcional da palavra - um médico que se ocupe do problema da saúde geral de um povo, de um tempo, de uma raça, da humanidade —, tenha um dia a coragem de levar ao ápice a minha suspeita e de ousar a proposição: em todo o filosofar até agora nunca se tratou de "verdade", mas de algo outro, digamos saúde, futuro, crescimento, potência, vida... ${ }^{26}$

Entramos aqui no terreno conceitual da tentativa de desvelamento do disfarce inconsciente das necessidades fisiológicas. A fisiologia nada mais seria que uma interpretação do corpo. Nesse contexto, devemos entender o termo fisiologia como a dinâmica impulsional e o corpo como uma configuração de impulsos que lutam por mais potência. Em outras palavras, temos como pano de fundo o conceito de vontade de potência [Wille zur Macht]..$^{27}$ Assim, podemos entender que o aforismo 23 de Para além de Bem e Mal fornece a doutrina que esse médico deve seguir: uma morfologia e doutrina do desenvolvimento da vontade de potência [Morphologie und Entwicklungslehre des Willens zur Macht]. Essa doutrina, segundo o filósofo alemão, é uma autêntica fisiopsicologia [PhysioPsychologie], um caminho para uma abordagem profunda dos problemas. Uma abordagem inseparável do problema da cultura, e Nietzsche considera-se o primeiro a entender a cultura como um problema e a investigar quais caminhos promovem efetivamente sua elevação: " $\mathrm{E}$, eu falo seriamente, ninguém antes de mim conhecia o reto caminho, o caminho para cima: é somente a partir de mim que existe novamente esperanças, tarefas, caminhos para prescrever à cultura [Cultur] - eu sou seu alegre mensageiro... E, assim, eu sou um destino [Schicksal $]. . .{ }^{28}$ Para cumprir esse destino de contribuir com a elevação da cultura europeia, há que se conhecer as etapas do desenvolvimento da cultura.

Podemos considerar que o que chamamos "ciclo vital da cultura"29 é antecipado pelos climas espirituais [geistige Klimata] do parágrafo I88 de $O$ Andarilho e sua Sombra. Nesse aforismo, as diferentes culturas [Culturen] são diferentes climas espirituais, sendo que cada um é particularmente danoso ou salutar para este ou aquele organismo. ${ }^{30} \mathrm{O}$ conhecimento da história das diferentes culturas é uma espécie de farmacologia, uma doutrina dos remédios que o médico deve utilizar para enviar cada um ao clima que lhe for mais propício, seja temporariamente, seja

26 A gaia Ciência, "Prefácio", \$2, KSA 3.349.

27 Para maiores detalhes da noção de vontade de potência, cf. Marton, 2000, pp. 4I-72.

28 Ecce Homo, "Crepúsculo dos ídolos: Como filosofar com o martelo", \$2, KSA 6.355.

29 Sobre nossa proposta de "ciclo vital da cultura", cf. Frezzatti, 2006, pp. 245-29I.

30 Sobre as metáforas climáticas em Nietzsche, Cf. Wotling, I995, pp. 245-272. 
definitivamente. Deve-se oferecer condições para que homens extremamente úteis vicejem: "a transplantação [Verpflanzung] espiritual e corporal como remédio". ${ }^{11}$ Com a história da cultura, teríamos um tratamento espiritual [Cur der Geister]; com uma geografia médica [medicinische Geographie], teríamos quais degenerações e enfermidades cada região ocasiona e quais curas fornece. ${ }^{32} \mathrm{~A}$ história das culturas, inicialmente apenas espiritual, vai desenvolver-se numa perspectiva fisiopsicológica, na qual o impulso não é nem espiritual nem corporal, mas é apenas um processo contínuo de tendência de crescimento de potência.

Embora Nietzsche tenha como uma de suas principais preocupações a elevação da cultura, o filósofo alemão é um crítico ferrenho das noções de progresso e de civilização. A cultura é produto da ação criadora e de imposição de valores e, portanto, produto do estabelecimento de verdades de um grande homem [grosse Mensch] ou gênio [Genie]. Esses valores são a expressão ou os sintomas de impulsos potentes e altamente hierarquizados que conseguiram ter livre curso. A civilização, por sua vez, expressa a domesticação [Zähmung] e decadência de impulsos: por não poderem crescer em potência, necessitam manter seu estado para evitar a dissolução derradeira. A idéia de progresso, para Nietzsche, faz parte das noções decadentes associadas à civilização. O filósofo não acredita em nenhuma forma de progresso e muito menos no progresso da humanidade como um todo: "Que nós não nos enganemos! O tempo corre avante, — nós gostaríamos de crer que tudo que estivesse no tempo também corresse avante... que o desenvolvimento [Entwicklung] fosse uma evolução [Vorwärts-Entwicklung]... Isso é a aparência enganosa que seduz os mais prudentes: mas o século XIX não é um progresso em relação ao Xviı" ${ }^{33}$ Isso faz com que Nietzsche pense em formas cíclicas e não lineares

3I O Andarilho e sua Sombra $\$$ I88, KSA 2.634.

32 Ideias como essa aparecem em Ecce Homo, por exemplo: "Agora, quando, após longo exercício, leio em mim os efeitos de origem climática e meteorológica, como em um instrumento muito sensível e confiável, e já numa curta viagem, tal como de Turim a Milão, posso verificar fisiologicamente em mim a alteração em graus da umidade do ar, penso com horror no fato inquietante de que minha vida, durante os últimos dez anos, anos com perigo de vida, passou-se sempre em lugares errados e francamente proibidos para mim" (Ecce Homo, "Por que sou tão esperto", \$2, KSA 6.282-283); e "A noção de 'deus' inventada como antagonista à vida — , nela tudo nocivo, venenoso, caluniador, toda inimizade mortal contra a vida, associados em uma horrível unidade! A noção de 'além', de 'mundo verdadeiro', inventada para depreciar o único mundo que existe — para não deixar à nossa realidade terrena nenhum alvo, nenhuma razão, nenhuma tarefa! $\mathrm{A}$ noção de 'alma', 'espírito', por fim ainda 'alma imortal', inventada para desprezar o corpo, torná-lo doente — 'santo' —, para colocar uma terrível leviandade em todas as coisas que merecem seriedade na vida, as questóes de alimentação, habitação, dieta espiritual, tratamento dos doentes, asseio, clima!" (Ecce Homo, "Por que sou um destino", \$ 8, KSA 6. 373-374).

33 Fragmento Póstumo Is [8] da primavera de I888, KSA I3.408. 
para entender o desenvolvimento (Entwicklung): "É necessário que a humanidade viva em ciclos; única forma durável. Não é necessário que a cultura [Cultur] dure o máximo possível, mas que ela seja o máximo possível breve e elevada" ${ }^{34}$ Nietzsche quer afastar toda meta teleológica e, assim, o processo do vi-a-ser se desenrola como a sequência infinita de vários ciclos, já que o mundo não teve começo e nem terá fim. ${ }^{35}$ Além disso, o ciclo da cultura segue o ciclo da própria vida.

O desenvolvimento cíclico da cultura não está explicitado nos textos do filósofo alemão. Contudo, podemos auferir esse desenvolvimento da maneira que Nietzsche apresenta as características da cultura superior, da cultura tardia (spät) ou da última fase ou ainda envelhecida e da transformação de uma determinada cultura. Nesse sentido, deve ser levado em conta o parágrafo 262 de Para além de Bem e Mal: um povo seleciona as características morais e culturais que permitem sua expansão frente aos desafios. ${ }^{36}$ Em cada cultura, foram desenvolvidas, devido às duras condições e às lutas com os vizinhos ou com os oprimidos rebelados, características que lhe permitiram vencer e evitar o risco de ser exterminada. As propriedades que propiciaram a vitória são fixadas através de uma moral aristocrática e cultivadas como virtudes. Com o tempo, contudo, uma situação tranquila é atingida: não há mais vizinhos para serem dominados e os recursos existem em abundância. A diminuição da pressão sobre o grupo alivia a rigidez da disciplina e a tensão exercida pelos antigos valores. A variação do tipo fixado aumenta, tanto o refinamento quanto a degeneração: não há mais uma pressão seletiva, há um desvio das virtudes antigamente criadas e o indivíduo atreve-se a isolar-se e separar-se do resto. Os indivíduos passam agora a competir entre si, afastados que estão da antiga moral, pois esta não mais modela nem mais limita. Cada indivíduo passa a produzir sua própria legislação, seus próprios valores e suas próprias estratégias de desenvolvimento e conservação. Transbordam, ao mesmo tempo, todas as potencialidades da raça, numa luta por crescimento, a qual o filósofo alemão compara com a explosão de vida numa floresta tropical (plantas sobrepondo-se umas sobre as outras em busca de luz). É nesse momento agudo que surge novamente a ameaça, o obstáculo, a dificuldade, a pressão seletiva — "a mãe da moral": a agressão parte do conterrâneo, do familiar, dos próprios impulsos. Essa situação pode se desenrolar no desenvolvimento de novos tipos e na criação de novos valores por aqueles capazes de enfrentar essa tarefa.

34 Fragmento Póstumo 2 [5] do verão-outono de I882, KSA I0.44-45.

35 Cf. Fragmento Póstumo I4 [I88] da primavera de I888, KSA I3.374-376.

36 O aforismo 262 de Para além de Bem e Mal (KSA 5.2I4-2I7) significa, para nós, a passagem da adaptação funcional de Wilhelm Roux para a filosofia de Nietzsche, cf. Frezzatti, 20I4b, pp. 88-90 e I24-I33. 
A estabilização, ou seja, a ausência de desafios coloca a cultura diante de uma encruzilhada: de um lado, a estagnação, permanecer em uma situação tranquila sem obstáculos, sempre igual, sem desenvolver potencialidades; de outro, a oportunidade de superação, de desenvolver uma nova potencialidade, enfrentar um novo desafio. Para o filósofo alemão, a moral que serve para consolidar uma cultura deve ser, a seu tempo, abandonada. Cada ciclo inicia-se com a imposição de uma perspectiva e termina com sua superação, ou seja, com a imposição de uma nova perspectiva, que é o início do ciclo seguinte. Esses ciclos se sucedem indefinidamente. A conservação de uma perspectiva impede o surgimento de um novo ciclo, significando estagnação. A cultura que aparenta força por sua persistência é, na verdade, decadente. ${ }^{37}$

As fases do desenvolvimento cíclico da cultura incluem um período de juventude (em que as forças ainda não atingiram seu máximo de potência), um período de apogeu (resultado de um processo de elevação da cultura, no qual atingimos o que Nietzsche chama cultura elevada ou superior) e um período em que a cultura está debilitada (cultura tardia). Nessa última fase da cultura, encontramos o que chamamos de encruzilhada: rompe-se a cultura vigente, o que possibilita a implantação de uma nova cultura, isto é, um possível processo de elevação, ou conserva-se a cultura vigente, o que impede a elevação e a obtenção de uma cultura superior. A cultura superior ou elevada é superior ou elevada em relação à cultura vigente. Dessa forma, o próprio processo de superação de uma cultura decadente e o estabelecimento de uma nova cultura, ou seja, de um novo conjunto de características, de uma nova perspectiva, de uma nova moral, de um novo processo seletivo, é entendido, por nós, como o processo nietzschiano de elevação, o qual só pode ocorrer se houver aumento de potência dos impulsos envolvidos.

Ao considerar as fases culturais, o médico ou o fisiopsicólogo nietzschiano pode recorrer a uma tipologia das culturas, pois o movimento cíclico, embora seja diferente, em sua expressão, em cada cultura, tem como possibilidade a mesma sequência de fases. Essa tipologia está calcada na configuração de impulsos de cada fase, ou seja, no grau hierárquico do conjunto de impulsos: dispersão enquanto decadência e forte hierarquia ou direção definida enquanto superioridade. Essa tipologia é uma face da crítica nietzschiana ao progresso: a humanidade não evolui para o melhor, para o mais forte ou para o superior.

É nesse sentido que o filósofo alemão compara a Europa de sua época com outras épocas de "cansaço filosófico", cujo termo utilizado para representá-lo é "budismo" ${ }^{38}$ Assim, culturas tardias, elevadas, em elevação ou decadentes

37 Cf. Fragmento Póstumo 24 [28] inverno I883/I884, KSA IO.66I-662.

38 Cf. Fragmento Póstumo Io [190] do outono de I887, KSA I2.569-570. 
são comparadas, agrupadas e hierarquizadas segundo seu estado "fisiológico". O predomínio que a Alemanha poderia ter sobre a Europa é justificada por sua "barbárie". ${ }^{39} \mathrm{O}$ fato de a França, uma cultura tardia ou envelhecida, ser a vanguarda da cultura é um sintoma da decadência européia. Nietzsche indica que a Rússia, outra cultura na fase "bárbara", ou seja, de impulsos potentes, teria condiçôes de dominar a Europa e a Ásia, inclusive a China e a Índia. Mas, indica ainda o filósofo, se a Europa cair na mão do rebanho, isto é, se se render à cultura tardia, será o fim da cultura européia: o filósofo alemão sugere, caso isso aconteça, salvar a cultura alojando-a em lugares distantes, por exemplo, o México.

É com relação à fase tardia da cultura que mais frequentemente Nietzsche apresenta sua tarefa de superar a cultura decadente. A fase da cultura tardia, serôdia ou envelhecida [spät Cultur] refere-se ao período em que os desafios não existem ou não estimulam mais. Seus homens não possuem mais uma característica marcante, o que provoca uma luta de instintos e critérios de valor antagonistas: não há mais uma direção fortemente definida, uma perspectiva, um estilo. O homem tardio, em geral, é débil, sua aspiração é o cessar de toda luta, sua felicidade é o repouso e a tranquilidade, há a busca de tranquilizantes cristãos e epicuristas. ${ }^{40}$ Para Nietzsche, a civilização [Civilisation] enquanto domesticação dos impulsos coincide com a cultura tardia. O que se considera "progresso" (a diminuição dos instintos hostis) é apenas uma das consequências da diminuição geral de vitalidade [Vitalität]. ${ }^{41}$ A cultura tardia caracteriza-se pelo nivelamento dos homens. É a época do filisteu da formação [Bildung] e da cultura [Cultur]: "O máximo possível e o mais rápido possível”" tudo indiscriminadamente e sem um critério de seleção. Esse modo de existência é sintoma da ausência do predomínio de um impulso ou de um conjunto de impulsos que imprima um estilo, uma perspectiva.

O que chamamos de ciclo vital da cultura é uma eterna sucessão de culturas e, em cada uma delas, uma sequência limitada de estágios culturais: cada um deles é um sintoma de uma configuração ou arranjo de impulsos que lutam eternamente entre si por mais potência. Cada cultura, a princípio, surge superando a anterior, cresce em potência, entra em declínio e é superada por sua sucessora, e assim por diante. Não há uma cultura determinada e única a ser atingida: o ciclo vital da

39 Cf. Fragmento Póstumo 25 [II2] da primavera de I884, KSA II.4I-42. "Barbárie" e "bárbaro" se referem a impulsos em processo de crescimento de potência. Opõem-se à noção de domesticação (Zähmung), ou seja, de enfraquecimento dos impulsos. Para Nietzsche, o homem civilizado é um animal domesticado.

40 Cf. Para além de Bem e Mal \$200, KSA 5.I2O-I2I.

4I Cf. Crepúsculo dos Ídolos, "Incursões de um extemporâneo", \ 37, KSA 6.I36-I39.

42 Fragmento Póstumo 5 [I] Io de novembro de I882-fevereiro de I883, KSA IO.I88. 
cultura não visa a um fim ou a um estado final, mas é um processo eterno. Cada cultura fundada tem seu próprio estilo, sua própria perspectiva (certo arranjo ou configuração de impulsos). Mais cedo ou mais tarde, a des-hierarquização de impulsos, que abre caminho para a reconfiguração, o rearranjo ou a recombinação, dissolverá a velha cultura e propiciará o surgimento de uma nova cultura, de um novo estilo, se houver acúmulo de forças por meio da luta dos impulsos. Enfim, dessa forma, pode-se dar oportunidade à criatividade humana se manifestar por meio da diversidade de culturas. O principal papel do médico filosófico está ligado, portanto, a permitir que as várias possibilidades humanas dinâmicas e antidogmáticas se manifestem.

Nietzsche associa várias figuras àquela do médico, não apenas o fisiopsicológo. Em momentos distintos de sua obra, temos o médico como: filósofo, educador, artista, religioso, filólogo, historiador e psicólogo. Alguns tipos nietzschianos elevados devem ter uma mescla de qualidades que inclui aquelas do médico. Em Miscelâneas de Opiniōes e Sentenças $₫$ I80, Nietzsche narra uma visão que acredita levantar uma ponta do véu do futuro, no qual surgiria uma virtude única resultante da fusão de várias virtudes: "Um mais novo e mais pleno desabrochar e florescer do ideal de mestre, no qual o clérigo, o artista [Künstler] e o médico, o sabedor e o sábio amalgamam-se". ${ }^{43} \mathrm{O}$ próprio Zaratustra deve incorporar algo do médico: "Zaratustra 3. A grande consagração do novo ser-médico-sacerdote-médico [Arzt-Priester-Lehrer-Wesen], que precede o além-do-homem [Übermensch]". ${ }^{44}$ De qualquer forma, busca-se o florescimento da cultura superior e a rejeição da domesticação dos impulsos humanos.

\section{Referências}

Frezzatti Jr., W. A. A fisiologia de Nietzsche. A superação da dualidade cultural biologia. Ijuí: Editora Unijuí, 2006.

Frezzatti Jr. "Nietzsche e Théodule Ribot: Psicologia e superação da metafísica". Natureza humana, v. I2 (2), pp. I-28, 2010.

Frezzatti Jr. "Nietzsche e la scienza: la fisiopsicologia come critica alla metafisica". In: Busellato, S. (Org.). Nietzsche dal Brasile: Contributi alla Ricerca contemporanea. Trad. G. Micheli, F. Nacci, S. Busellato. Pisa: ETs, 20I4, pp. $185-200$.

Frezzatti Jr. Nietzsche contra Darwin. $2^{a}$ edição ampliada e revista. São Paulo: Loyola, 20I4b.

43 KSA 2.458.

44 Fragmento Póstumo 26 [223] do verão - outono de I884, KSA II.208. 
Marton, S. Nietzsche: das forças cósmicas aos valores humanos. $2^{\mathrm{a}}$ ed. Belo Horizonte: UFMG, 2000.

NAsser, E. "O destino do gênio e o gênio enquanto destino: o problema do gênio no jovem Nietzsche”. Cadernos Nietzsche, v. 30, pp. 287-302, 2012.

Nietzsche, F. W. Sämtliche Werke. Kritische Studienausgab. G. Colli und M. Montinari (Hg). Berlin: Walter de Gruyter, I999, I5 Bd.

Silva Jr., I. da. Em Busca de um Lugar ao Sol: Nietzsche e a Cultura alemã. São Paulo, Ijuí: Discurso, Unijuí, 2007 (Col. Sendas \& Veredas).

Wotling, P. Nietzsche et le problème de la civilization. Paris: PUf, I995. Em português: Wotling, P. Nietzsche e o problema da civilização. São Paulo: Barcarolla, 20I3 (Col. Sendas \& Veredas). 